\title{
Differentiation Among Blumeria graminis f. sp. tritici Isolates Originating from Wild Versus Domesticated Triticum Species in Israel
}

\author{
Roi Ben-David, Ryan Parks, Amos Dinoor, Evsey Kosman, Thomas Wicker, Beat Keller, and Christina Cowger
}

First author: Department of Vegetables and Field Crops, Institute of Plant Sciences, ARO-Volcani Center, Bet Dagan 5025000, Israel; second and seventh authors: United States Department of Agriculture-Agricultural Research Service, Department of Plant Pathology, North Carolina State University, Raleigh 27695; third author: The Department of Plant Pathology and Microbiology, The Robert H. Smith Faculty of Agriculture, Food and Environment, The Hebrew University of Jerusalem, Rehovot 7610001, Israel; fourth author: Institute for Cereal Crops Improvement (ICCI), The George S. Wise Faculty for Life Sciences Tel Aviv University, Tel Aviv 69978, Israel; and fifth and sixth authors: Department of Plant and Microbial Biology, University of Zurich, Zollikerstrasse 107, CH-8008 Zurich, Switzerland.

Accepted for publication 14 March 2016.

\begin{abstract}
Ben-David, R., Parks, R., Dinoor, A., Kosman, E., Wicker, T., Keller, B., and Cowger, C. 2016. Differentiation among Blumeria graminis f. sp. tritici isolates originating from wild versus domesticated Triticum species in Israel. Phytopathology 106:861-870.

Israel and its vicinity constitute a center of diversity of domesticated wheat species (Triticum aestivum and T. durum) and their sympatrically growing wild relatives, including wild emmer wheat (T. dicoccoides). We investigated differentiation within the forma specialis of their obligate powdery mildew pathogen, Blumeria graminis f. sp. tritici. A total of 61 $B$. graminis f. sp. tritici isolates were collected from the three host species in

(simple-sequence repeats and single-nucleotide polymorphisms). All isolates were virulent on at least some genotypes of all three wheat species tested. All assays divided the $B$. graminis f. sp. tritici collection into two distinct groups, those from domesticated hosts and those from wild emmer wheat. One-way migration was detected from the domestic wheat $B$. graminis $\mathrm{f}$. sp. tritici population to the wild emmer $B$. graminis $\mathrm{f}$. sp. tritici population at a rate of five to six migrants per generation. This gene flow may help explain the overlap between the distinct domestic and wild $B$. graminis f. sp. tritici groups. Overall, B. graminis f. sp. tritici is significantly differentiated into wild-emmer and domesticated-wheat populations, although the results do not support the existence of a separate f. sp. dicocci.
\end{abstract} four geographic regions of Israel. Genetic relatedness of the isolates was characterized using both virulence patterns on 38 wheat lines (including 21 resistance gene differentials) and presumptively neutral molecular markers
Additional keywords: Triticum turgidum subsp. dicoccoides, virulence analysis tool.
The high degree of host specialization found in powdery mildews reflects the advanced evolution of these obligate biotrophic pathogens (Eshed and Wahl 1970; Wyand and Brown 2003). The cereal powdery mildews (formerly Erysiphe graminis, now Blumeria graminis) are thought to have spread and evolved in tandem with their hosts (Oberhaensli et al. 2011), radiating phylogenetically in response to the development and geographic spread of cereal crops since Neolithic times (Zohary and Hopf 2000). One of the earliest cereal mildew taxonomic schemes, developed by Marchal (1902), assumed that infection by one physiological form was limited to one single host genus. Based on this, seven formae speciales were delimited: B. graminis f. sp. hordei on Hordeum species, f. sp. tritici on Triticum spp., f. sp. secalis on Secale spp., f. sp. avenae on Avena spp., and three formae speciales on wild grasses (this was extended to eight formae speciales by Oku et al. [1985]).

With the aid of molecular markers, nine distinct groups within B. graminis have been identified, and isolates from Secale, Triticum, and Agropyron species are closely related (Inuma et al. 2007; Troch et al. 2014; Wyand and Brown 2003), indicating that these taxa have only recently diverged from one another. In fact, $B$. graminis host range is continually evolving, as evidenced by

Corresponding author: R. Ben-David; E-mail address: roib@volcani.agri.gov.il

*The $\boldsymbol{e}$-Xtra logo stands for "electronic extra" and indicates that two supplementary tables are published online.

http://dx.doi.org/10.1094/PHYTO-07-15-0177-R

This article is in the public domain and not copyrightable. It may be freely reprinted with customary crediting of the source. The American Phytopathological Society, 2016. separate clusters (based on virulence spectra) detected for isolates from wheat versus triticale ( $\times$ Triticosecale) (Walker et al. 2011). Based on $\beta$-tubulin phylogeny, isolates from T. aestivum, T. durum, and $T$. dicoccoides were closely related to each other and to those from genera Secale, Triticale, and Agropyron (Troch et al. 2014). Troch et al. (2014) proposed that the crop-infecting B. graminis clades should remain formae speciales but those infecting wild relatives should not.

Using seedling inoculations, Eshed and Wahl (1970) determined that Israeli $B$. graminis f. sp. tritici populations had a wide host range ( 16 of 60 host genera they tested). They proposed that the host range in Israel was broader than elsewhere and attributed this extra breadth to correlated coevolution, under which the genetic interrelatedness and extreme diversification of grasses in their center of origin called forth a correspondingly high level of genetic differentiation and variability in the matching $B$. graminis population. Further divergence of $B$. graminis into two subformae (from wild emmer and cultivated wheat) was suggested by Eshed et al. (1994), based on a detailed study of $B$. graminis f. sp. tritici isolates.

Using neutral markers, Parks et al. (2009) assayed a set of 28 B. graminis f. sp. tritici isolates from Israel in a comparison with United States and United Kingdom powdery mildew populations. In contrast to their expectation of high diversity among the Israeli $B$. graminis f. sp. tritici isolates, originating in or near the center of origin of wheat, the authors found that haplotype richness was greater in the United Kingdom sample. This finding was attributed to the larger effective populations in the cooler climate of the United Kingdom, which is more conducive to powdery mildew than the arid Middle East.

Israel and vicinity is a center of diversity of wild emmer wheat ( $T$. dicoccoides $=$ Triticum turgidum subsp. dicoccoides Desf.) 
(Harlan and Zohary 1966; Salamini et al. 2002), which is distributed sympatrically with commercial fields of domesticated wheat (both $T$. aestivum and $T$. durum $=T$. turgidum subsp. durum). T. dicoccoides was first cultivated around 10,000 years ago in this region, giving rise to $T$. durum and, through a cross with Aegilops tauschii, to T. aestivum about 7,000 to 9,000 years ago (Peng et al. 2011; Salamini et al. 2002). Both Triticum species serve as hosts of $B$. graminis f. sp. tritici. Israel grows about 100,000 hectares of T. aestivum and 4,000 hectares of T. durum annually, with wild $T$. dicoccoides populations often occurring adjacent to or near commercial fields (Fig. 1), often in intimate mixture with other wild cereals, such as wild barley (Hordeum spontaneum) and wild oat (Avena spp.) (Fig. 2). Recent phenotypic screening of a broad, diverse collection of Triticum germplasm with several isolates of B. graminis f. sp. tritici resulted in a clear pattern of host adaptation; isolates sampled from wild wheat had higher frequencies of virulence to wild wheat accessions than to domesticated wheat lines, while the reverse was true for isolates from domesticated wheat (Ben-David 2011; Ben-David et al. 2008). This pattern is probably the result of long-term plant-pathogen coevolution, and it is consistent with previously observed host specialization by $B$. graminis. Recently, Menardo et al. (2016) determined the genomic sequences of 19 $B$. graminis f. sp. tritici isolates. Based on the strong, host-based molecular differentiation within the $B$. graminis f. sp. tritici clade, they designated a new forma specialis, $B$. graminis f. sp. dicocci.

Thus, in the Israeli B. graminis f. sp. tritici population, evidence has been found for broad host range, limited genotypic diversity (at nonselected loci), and host specialization. Little is yet known about the evolutionary processes affecting the $B$. graminis $\mathrm{f}$. sp. tritici population in its presumed center of origin. The close physical mixing of the three Triticum host species provides a unique opportunity to examine pathogenic host range at the host species level.

In this study, we have evaluated a diverse collection of $B$. graminis f. sp. tritici isolates from Israel, using both phenotypic and molecular tools in order to (i) characterize the virulence and molecular diversity of the collection, (ii) test whether this diversity was associated with host and geographic origin, and (iii) determine the degree of host species specificity in B. graminis f. sp. tritici isolates originating from wild and domesticated hosts.

\section{MATERIALS AND METHODS}

Plant material and powdery mildew isolates. A set of 61 $B$. graminis f. sp. tritici isolates was collected from wild and domesticated Triticum species growing in or near Israel: 26 from T. aestivum, 16 from T. durum, and 19 from T. dicoccoides (Table 1;
Fig. 3). They originated from across Israel's Mediterranean zone $\left(31^{\circ} 25^{\prime}\right.$ to $\left.33^{\circ} 07^{\prime}\right)$ and are being maintained at the Hebrew University as part of the Eshed-Dinoor living mildew collection. All isolates were collected in Israel with one exception, isolate 52, which was collected from Dir-El-Balakh in the Gaza Strip (Table 1). Of the 61 isolates, 41 were collected in 1990 to 1993 and 20 in 2010. Isolates collected prior to 2010 were previously used in an analysis of population diversity comparing single-nucleotide polymorphisms (SNP) from the United States, United Kingdom, and Israel, and the remaining DNA was used for the present marker analysis (Parks et al. 2009). In 2010, additional isolates were collected in order to reduce potential bias from sample size differences among geographic regions and hosts of origin.

In addition, two $T$. aestivum-derived isolates that originated in the United Kingdom and Switzerland, respectively, were used in the study (JIW2 and 96224). The isolate A6 of B. graminis f. sp. hordei, the barley forma of the pathogen, came from the UZH collection (originally obtained from P. Schulze-Lefert, MPI Cologne) and was used as a reference in the SNP assay described below.

The Israeli isolates were collected from 38 locations (Table 1). In several locations, more than one isolate was collected: Amiad ( $n=4, T$. dicoccoides), Ein Hanaziv ( $n=4$, of which two were from

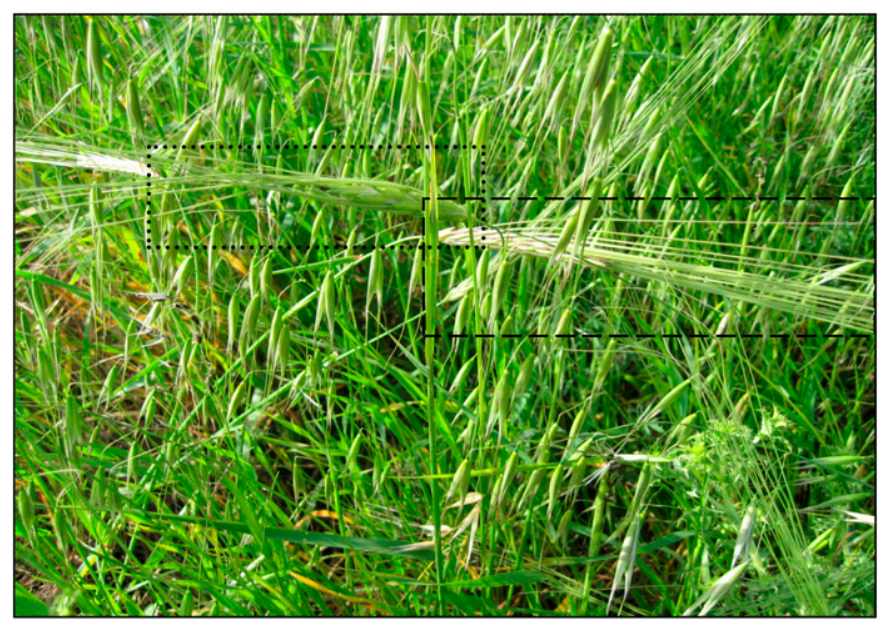

Fig. 2. Wild emmer wheat, Triticum turgidum subsp. dicoccoides, growing in its natural habitat (Mt. Gilboa, Israel) in a mixture with nonhost species of Blumeria graminis f. sp. tritici. A dotted black line frames wild wheat (T. dicoccoides) and a dashed black line frames wild barley (Hordeum spontaneum). Wild oats are also prominent.
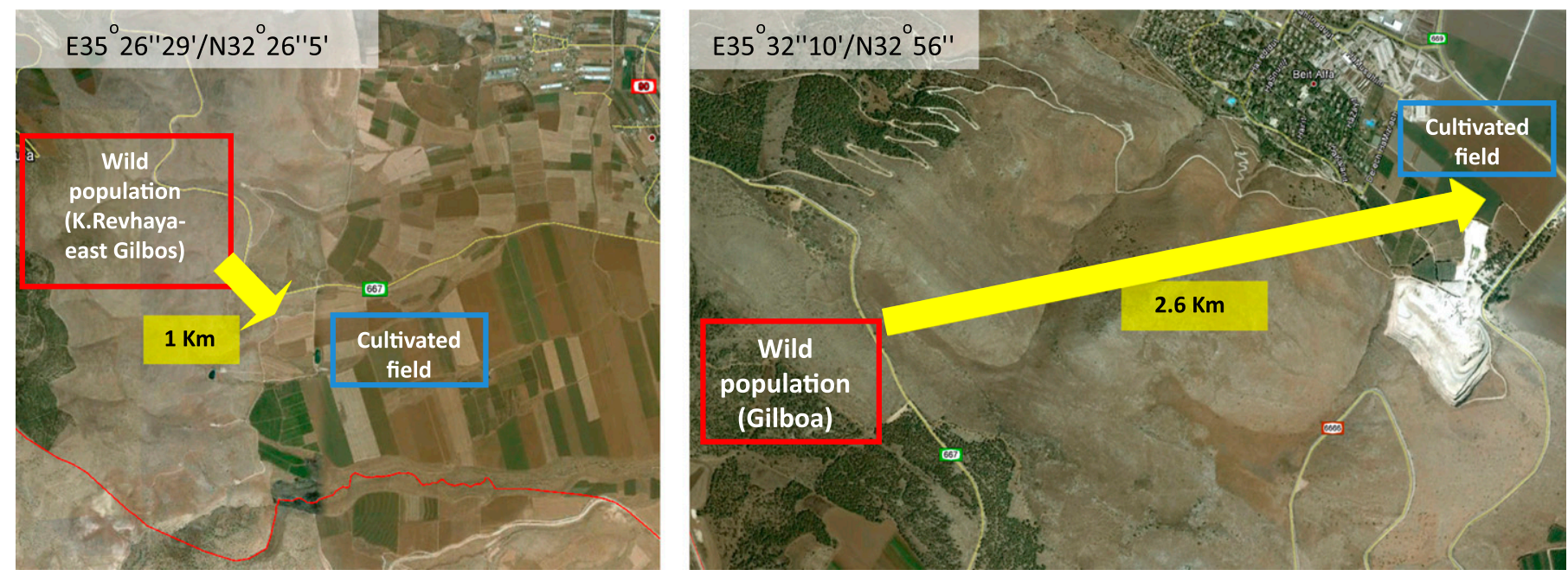

Fig. 1. Sympatric distribution of wild emmer wheat (Triticum dicoccoides) populations and cultivated wheat in Mount Gilboa, Israel. 
T. aestivum and two from T. durum), Hula ( $n=7$, of which six were from $T$. aestivum and one from $T$. durum), Gilboa $(n=2$, T. dicoccoides), Nahal $\mathrm{Oz}(n=7$, of which five were from T. aestivum and two from T. durum), Negba $(n=2$, one from T. aestivum and one from T. durum), and Tel-Aviv ( $n=2$, from a T. dicoccoides nursery, an artificial environment different from a natural wild emmer wheat habitat). In those locations where more than one isolate was collected from T. aestivum or T. durum, they were from different varieties at each location.

The four geographic regions and numbers of isolates collected in each were as follows: Northern Coastal Plain $(n=11)$, Eastern Galilee $(n=12)$, Emek Bet Shean $(n=10)$, and Mt. Judea and Plain $(n=28)$. The first three regions are in northern Israel. The Northern Coastal Plain is mainly lowlands ( $<100$ m elevation) adjacent to the

TABLE 1. Blumeria graminis f. sp. tritici isolates from wild or domesticated Triticum species included in the current study

\begin{tabular}{|c|c|c|c|c|c|c|}
\hline Isolate no. & Geographic region & Location & Triticum sp..$^{\mathrm{y}}$ & Cultivar name & Analysis $^{z}$ & Collection year \\
\hline 1 & Eastern Galilee & Hula & aes & Dari'el & SN, SS & 1990 \\
\hline 4 & Eastern Galilee & Hula & aes & Deganit & SS & 1990 \\
\hline 6 & Eastern Galilee & Hula & aes & Atir & SN, SS & 1990 \\
\hline 7 & Eastern Galilee & Hula & aes & Shafir & SN, SS & 1990 \\
\hline 8 & Eastern Galilee & Hula & dur & Bareket & SN, SS & 1990 \\
\hline 9 & Eastern Galilee & Hula & aes & 652 & SN, SS & 1990 \\
\hline 13 & Eastern Galilee & Hula & aes & 509 & SN, SS & 1990 \\
\hline 15 & Northern Coastal Plain & Yavor & dur & Inbar & SN, SS & 1990 \\
\hline 16 & Mt. Judea, Plain & Nahal Oz & dur & Inbar & SS & 1990 \\
\hline 20 & Emek Bet Shean & Ein Hanaziv & dur & Inbar & SS & 1991 \\
\hline 25 & Mt. Judea, Plain & Bet Dagan & dur & Inbar & SN, SS & 1991 \\
\hline 29 & Emek Bet Shean & Ein Hanaziv & aes & Shafir & SS & 1990 \\
\hline 30 & Mt. Judea, Plain & Talm Yafe & aes & Shafir & SS & 1991 \\
\hline 33 & Mt. Judea, Plain & Erez & aes & Deganit & & 1990 \\
\hline 36 & Mt. Judea, Plain & Lahav & aes & Deganit & SS & 1990 \\
\hline 37 & Mt. Judea, Plain & Nahal Oz & aes & Deganit & SS & 1990 \\
\hline 43 & Mt. Judea, Plain & Yesodot & aes & BetHashita & SS & 1991 \\
\hline 44 & Mt. Judea, Plain & Negev & aes & Miriam & SS & 1991 \\
\hline 47 & Mt. Judea, Plain & Saad & aes & BetLehem & SS & 1990 \\
\hline 50 & Mt. Judea, Plain & Nahal Oz & aes & Barkay & & 1990 \\
\hline 52 & Mt. Judea, Plain & DirElBalakh & dur & & & 1990 \\
\hline 58 & Eastern Galilee & Amiad & dic & & SN, SS & 1990 \\
\hline 61 & Eastern Galilee & Tabha & dur & Zenati Bouteille & SN, SS & 1990 \\
\hline 63 & Emek Bet Shean & Gilboa & dic & & SN, SS & 1990 \\
\hline 66 & Eastern Galilee & Amiad & dic & & SN, SS & 1990 \\
\hline 67 & Mt. Judea, Plain & Lahav & dur & Inbar & SS & 1990 \\
\hline 68 & Mt. Judea, Plain & Bet Dagan & aes & BetHash & SS & 1990 \\
\hline 70 & Mt. Judea, Plain & Beeri & aes & Deganit & SN, SS & 1990 \\
\hline 91 & Emek Bet Shean & Sde Eliahu & dur & Inbar & SN, SS & 1990 \\
\hline 92 & Mt. Judea, Plain & Tel Aviv & dic & & SS & 1992 \\
\hline 94 & Emek Bet Shean & Ein Hanaziv & aes & Deganit & SS & 1990 \\
\hline 95 & Emek Bet Shean & Ein Hanaziv & dur & Bareket & SN, SS & 1990 \\
\hline 96 & Mt. Judea, Plain & Negba & aes & sw50 & SN, SS & 1990 \\
\hline 97 & Mt. Judea, Plain & Negba & dur & 50 & SN, SS & 1990 \\
\hline 101 & Mt. Judea, Plain & Nahal Oz & aes & Dari'el & SS & 1990 \\
\hline 103 & Eastern Galilee & Amiad & dic & & SN, SS & 1990 \\
\hline 106 & Mt. Judea, Plain & Nahal Oz & aes & Atir & SS & 1990 \\
\hline 107 & Mt. Judea, Plain & Nahal Oz & aes & Shafir & & 1990 \\
\hline 108 & Mt. Judea, Plain & Nahal Oz & dur & Bareket & SS & 1990 \\
\hline 109 & Mt. Judea, Plain & Tel Aviv & dic & & & 1993 \\
\hline 113 & Eastern Galilee & Amiad & dic & W-B-1 & SN, SS & 1990 \\
\hline 201 & Northern Coastal Plain & Tzurit & dic & & SN, SS & 2010 \\
\hline 202 & Northern Coastal Plain & Haifa University & dic & & SN, SS & 2010 \\
\hline 203 & Northern Coastal Plain & Misgav & dic & & SN, SS & 2010 \\
\hline 204 & Northern Coastal Plain & Kfar-Masaryk & dur & Eylon & SN, SS & 2010 \\
\hline 205 & Mt. Judea, Plain & Kfar-Menahem & dur & Eylon & SN, SS & 2010 \\
\hline 206 & Mt. Judea, Plain & Neve Michael & dic & & SN, SS & 2010 \\
\hline 207 & Mt. Judea, Plain & Bet Meir & dic & & SN, SS & 2010 \\
\hline 208 & Emek Bet Shean & Gilboa & dic & & SS & 2010 \\
\hline 209 & Emek Bet Shean & K. Revhaya & dic & & SN, SS & 2010 \\
\hline 210 & Emek Bet Shean & G. Hamore & dic & & SN, SS & 2010 \\
\hline 211 & Emek Bet Shean & Merav & dic & & SN, SS & 2010 \\
\hline 212 & Mt. Judea, Plain & Shilat & dic & & SN, SS & 2010 \\
\hline 213 & Mt. Judea, Plain & Modihin West & dic & & SN, SS & 2010 \\
\hline 214 & Northern Coastal Plain & Akko & dur & Eylon & SS & 2010 \\
\hline 215 & Northern Coastal Plain & Barkai & dur & Eylon & SN, SS & 2010 \\
\hline 216 & Northern Coastal Plain & Ein Shemer & aes & Yuval & SS & 2010 \\
\hline 217 & Northern Coastal Plain & Kfar-Hasidim & aes & Galil & SN, SS & 2010 \\
\hline 218 & Northern Coastal Plain & Tel Far & aes & Ariel & SN, SS & 2010 \\
\hline 219 & Mt. Judea, Plain & Bizaron & aes & & SS & 2010 \\
\hline 220 & Northern Coastal Plain & Bet Oren & dic & & SN, SS & 2010 \\
\hline JIW2 & - & United Kingdom & aes & & SN, SS & 1990 \\
\hline 96224 & - & Switzerland & aes & & SN, SS & 1996 \\
\hline
\end{tabular}

y Wheat host: aes $=T$. aestivum, dur $=T$. durum, dic $=T$. dicoccoides .

$\mathrm{z}$ Type of assay: $\mathrm{SN}=$ single-nucleotide polymorphism analysis, $\mathrm{SS}=$ simple-sequence repeat analysis. 
Mediterranean Sea, the exception is Mount Carmel (546 m elevation). Eastern Galilee includes the lower eastern parts of the upper Galilee Mountains (200 m elevation) and their eastern border, the Hula Valley $(<70 \mathrm{~m})$. Emek Bet Shean includes the eastern valley farming region ( $-150 \mathrm{~m}$ elevation) with Mt. Gilboa (400 m elevation) on its southwest. Mt. Judea and Plain is a relatively vast region in central and southern Israel including the western foothills of Judean Mountains (400 to $600 \mathrm{~m}$ elevation), the Judea Plain, and the northern and western parts of the Negev Desert (50 to 150 m elevation).

Virulence characterization. The isolates from the EshedDinoor mildew collection were characterized for virulence by inoculating a set of wheat powdery mildew $(P m)$ differential lines $(n=$ $21)$, bread wheat cultivars $(n=5)$, durum wheat cultivars $(n=8)$, and wild emmer wheat accessions $(n=4)$ (Supplementary Table S1). The $P m$ differential lines mostly contained one $P m$ gene each, but in two cases, possessed two or three genes each. Bread wheat and durum wheat cultivars were chosen to represent cultivated Israeli germplasm (including T. durum landrace Zenati Bouteille). The

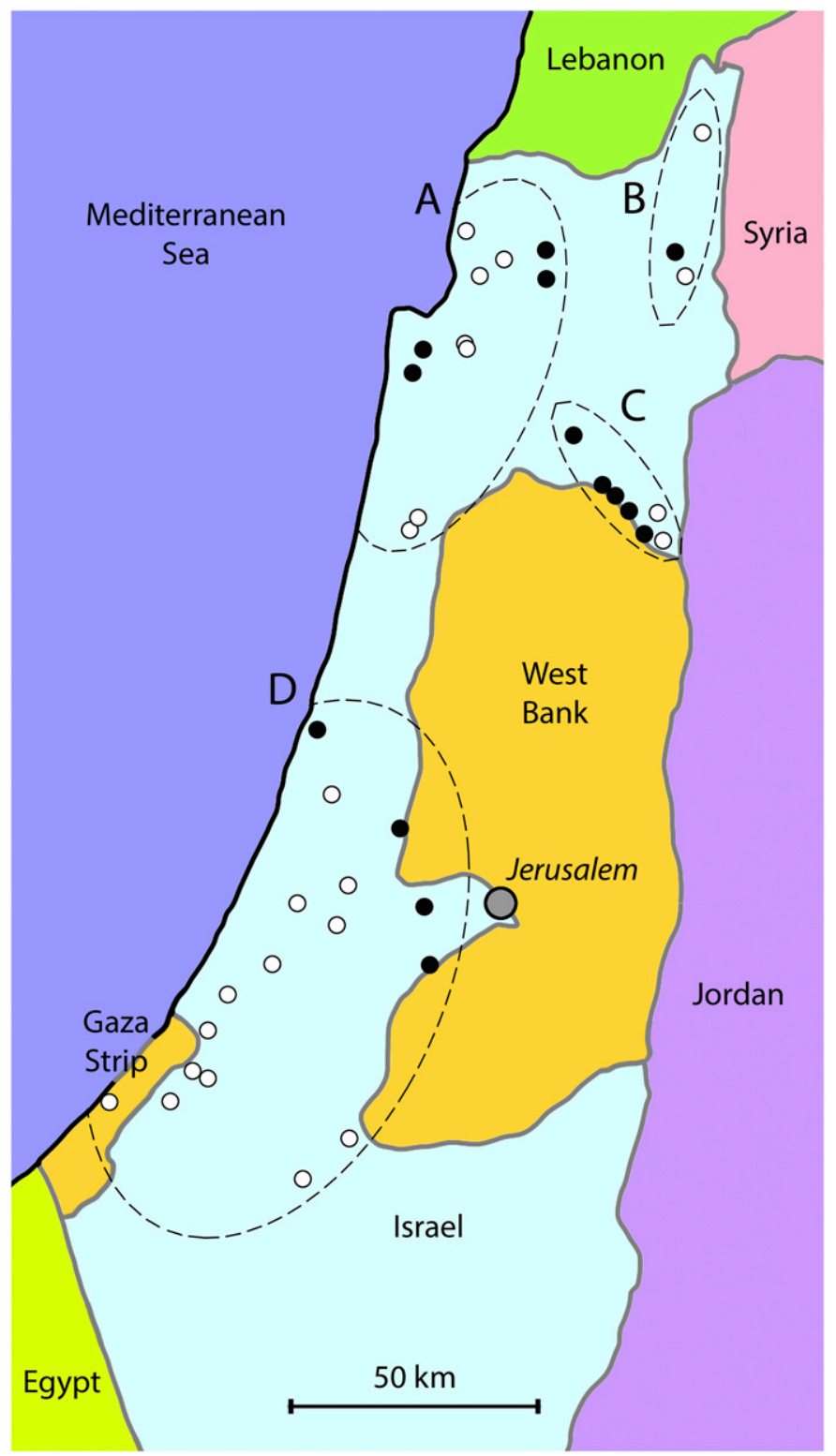

Fig. 3. Locations across Israel and surrounding regions where Blumeria graminis f. sp. tritici samples were collected from wild emmer wheat (filled circles) or cultivated wheat fields (open circles). The four geographic regions are marked with dashed black line: A, Northern Coastal Plain; B, Eastern Galilee; C, Emek Bet Shean; and D, Mt. Judea and Plain. tested genotypes also included several cultivars from outside of Israel (e.g., bread wheat cultivars Chinese Spring, Arina, and Forno; and durum wheat cultivars Cerco and Langdon). Wild emmer wheat accessions from Israel were selected arbitrarily.

All 61 isolates were tested on all cultivars. Inoculation and disease assessment were performed according to Hsam and Zeller (1997) and Ben-David et al. (2014) with two to four replicates. The infection types of powdery mildew were recorded on a scale of 0 to 4 : 0 indicated no visible symptoms, while a score of ' 0 ;' was recorded for necrotic flecks (hypersensitive response), and values of 1, 2, 3, and 4 signified highly resistant, resistant, susceptible, and highly susceptible reactions, respectively (Mains and Dietz 1930). Scores of 0 to 2 were grouped as resistant and scores of 3 to 4 as susceptible.

Molecular markers. Simple-sequence repeat (SSR) alleles were determined for a total of 58 isolates (Table 1). DNA extraction for these isolates followed a CTAB protocol as previously described (Cowger et al. 2016). Ten SSR markers (BGT1 to BGT10) were amplified with fluorescent labels as previously described (Parks et al. 2011). Resulting fragments were analyzed by Eton Biosciences, Inc. (Durham, NC) on an ABI 3730xl with size standard GS500LIZ. Fragments were manually sized using Peak Scanner version 1.0 (Applied Biosystems Inc., Carlsbad, CA). Raw fragment sizes with decimals were binned into alleles of expected periodicity, using TANDEM (Matschiner and Salzburger 2009). All analyses were performed on binned fragment sizes.

Four loci were investigated (two genic and two intergenic) based on two characterized loci in the B. graminis f. sp. tritici genome (Oberhaensli et al. 2011). SNPs were identified for 37 of the total sample of 63 isolates; the 37 isolates were those for which highquality sequence information was available at all four loci. Genomic DNA samples were extracted using a Qiagen DNeasy plant mini kit. On average, 500 to $600 \mathrm{bp}$ of good-quality sequence were obtained for each primer (about $1 \mathrm{~kb}$ per locus). Sequences were aligned using BioEdit software (www.mbio.ncsu.edu/BioEdit/page2.html). Analysis was performed using clustalW multiple alignment as implemented in BioEdit 7.1.3. The sequences were clustered and ordered by their similarity.

Statistical analyses. Virulence. The virulence scores were analyzed using the virulence analysis tool (VAT software) to characterize diversity within the collection and to identify different pathotypes (Schachtel et al. 2012) (https://en-lifesci.tau.ac.il/ profile/kosman/vat). In addition to assessment of descriptive parameters such as virulence frequency, pathotype frequency, and virulence complexity, the assignment-based approach to diversity analysis (Kosman 1996, 2014; Kosman and Leonard 2007) was employed for comparison of isolates from different host species and from different geographic regions. Dissimilarity between virulence patterns of isolates was estimated with the simple mismatch coefficient, and the corresponding Kosman's estimates were calculated for diversity within $(K W)$ and distance between $(K B)$ populations. A permutation test was performed with 1,000 random partitions of the data for differentiation statistics based on the $K W$ diversity according to Equations 20 to 22 in Kosman (2014) as explained by Kosman et al. (2014). Diversity (always nonnegative for $K W$ ) within a total pool of isolates and the weighted average diversity within $k$ populations were estimated for the original subdivision and for 1,000 random partitions of the total population into $k$ groups containing the same numbers of isolates as in the original populations. The null hypothesis that the populations were not genetically differentiated was rejected if, in at least 950 of the 1,000 cases, the differentiation statistic obtained for the random partitions was less than the differentiation statistic obtained for the original partition $(P<0.05)$.

Using the unweighted pair group method with arithmetic means, a dendrogram for 61 isolates was derived based on simple mismatch dissimilarity and using the SAHN module of the NTSYSpc package, v. 2.1 (Exeter Software). The cophenetic correlation was calculated (COPH and MXCOMP modules of NTSYSpc) to assess correspondence between the dendrogram structure and the original distance 
matrix upon which the clustering was based (goodness of fit of clustering by the dendrogram).

Molecular data. Analyses with the SSR markers were conducted on the 58 isolates for which data were of high quality. Relationships among isolates were analyzed using the stepwise mutation model. Dissimilarity between SSR patterns was estimated on the basis of allele sizes (number of tandem repeats) under the assumption that the mutation rate varied from locus to locus (Appendix, Equation A1). To evaluate potential separation of isolates derived from different hosts, the obtained matrix of dissimilarities was subjected to a principal coordinate analysis (PCoA), and the corresponding plot was generated with GenAlex 4 software. Population subdivision based on host geographic origin was assessed by applying to SSR fragment sizes an exact G-test as implemented in Genepop version 4.0.11, with 10,000 de-memorization steps in 100 batches and 5,000 iterations per batch.

An additional test of population subdivision was performed, using the SSR data in Structure 2.3.3, under a model assuming independent allele frequencies among populations and genetically admixed individuals. Data were fitted to a model assuming $\mathrm{K}$ values of 1 to 5 , where $\mathrm{K}$ is the optimum number of populations given the data. Ten independent analyses per $\mathrm{K}$ value were executed, and each independent run consisted of 1,000,000 steps with a 10\% burn in. The optimal $\mathrm{K}$ was determined using the Evanno method (Evanno et al. 2005) via Structure Harvester (Earl and vonHoldt 2012).

Migration. Comparisons of effective population sizes and estimates of migration among host populations were made using Migrate-N version 3.3.1 (Beerli and Palczewski 2010). The SSR and SNP markers were analyzed separately, as the evolution of the markers was presumed to have occurred on different evolutionary time scales. Migrate-N utilizes a coalescent approach for estimation of the mutation-scaled effective immigration rate $(\Theta)$ and the mutation-scaled effective population size (M). For haploids, $\Theta=$ $2 \mathrm{Ne} \mu$, where $2 \mathrm{Ne}$ is the effective population size and $\mu$ is the mutation rate per marker per generation (per site per generation for SNPs). Parameter $M$ is a ratio of immigration to mutation $(\mathrm{m} / \mu$, where $\mathrm{m}$ is the immigration rate per generation from a source to a sink population). Multiplication of estimates $\Theta$ and M (divided by 2 for a haploid organism) provides a pergeneration estimate of the number of migrants between two populations.

Due to the data requirements of Migrate-N, DNA sequences were edited and polymorphisms were only analyzed for that portion of each sequence having base calls with high reliability in all individuals. The resulting sequences were as follows: $349 \mathrm{bp}$ for primer I12G2-F, 349 bp from primer I12I9-F, 316 bp from I12I9-R, 500 bp from C19G5-F, 520 bp from C19G5-R, 483 bp from C19I4-F, and $406 \mathrm{bp}$ from C19I4-R. Data were concatenated in chromosomal order into two contigs numbered 12 and 19. Gaps between concatenated sequences were ignored.

\section{RESULTS}

Virulence analysis. Virulence frequencies to most $P m$ alleles were very similar between isolate populations from T. aestivum and $T$. durum, while frequencies of virulence of $T$. dicoccoides isolates to the same alleles were significantly lower (Fig. 4). The exceptions were $P m 1 b, P m 5 b$, and $P m 22$; virulence to those $P m$ genes was equal or higher among wild emmer-derived isolates. Among isolates originating from T. aestivum or T. durum, almost every isolate had a unique pathotype, while the proportion was lower for isolates from T. dicoccoides (Table 2). Complete virulence/avirulence data for the isolates are given in Supplementary Table S1.

No geographic pattern was observed in the virulence data. By the differentiation test based on $K W$, the null hypothesis that the

TABLE 2. Virulence complexities (VC) for Blumeria graminis f. sp. tritici isolates from two domestic and one wild Triticum species in Israel

\begin{tabular}{lccc}
\hline Host & No. of isolates & No. of haplotypes & $\mathrm{VC}^{\mathrm{z}}$ \\
\hline T. aestivum & 26 & 25 & $13.34 \mathrm{a}$ \\
T. durum & 16 & 16 & $11.37 \mathrm{a}$ \\
T. dicoccoides & 19 & 12 & $5.47 \mathrm{~b}$ \\
TOTAL & 61 & & \\
\hline
\end{tabular}

$\mathrm{z}$ VC values followed by different letters are significantly different from each other $(P<0.0001)$.

TABLE 3. Kosman genetic distances between $(\mathrm{KB})$ and diversity within (KW, along the diagonal) groups of Blumeria graminis f. sp. tritici originating from Triticum aestivum, T. durum and T. dicoccoides in Israel, based on virulence data

\begin{tabular}{lccc}
\hline & \multicolumn{3}{c}{ B. graminis f. sp. tritici isolates from } \\
\cline { 2 - 4 } & T. aestivum & T. durum & T. dicoccoides \\
\hline T. aestivum & 0.321 & 0.189 & 0.384 \\
T. durum & $\ldots$ & 0.413 & 0.347 \\
T. dicoccoides & $\ldots$ & $\ldots$ & 0.377 \\
\hline
\end{tabular}

\section{Virulence frequency}
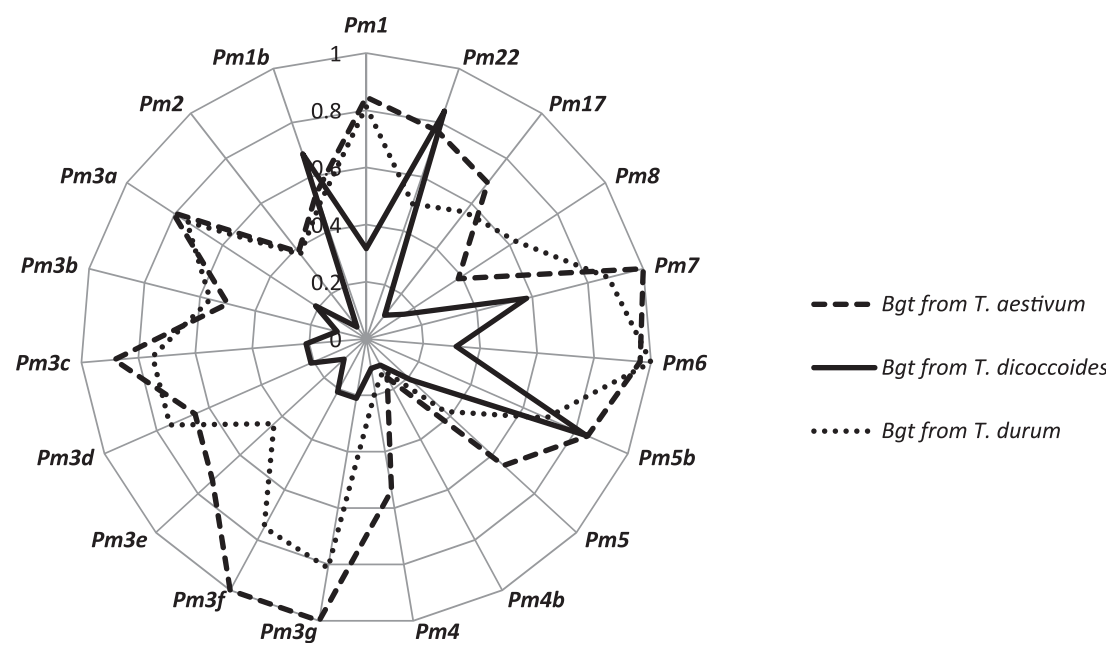

Fig. 4. Frequencies of virulence to individual Pm genes of 61 Blumeria graminis f. sp. tritici isolates collected in Israel and vicinity from wild (T. dicoccoides) and domesticated Triticum species collected in 1990 to 1993 or 2010. 
populations from the four regions were not genetically differentiated was not rejected (data not shown; $P=0.235$ ).

However, isolates were clearly differentiated by host of origin. Larger genetic distances were observed between isolates from $T$. dicoccoides and those from both T. aestivum (0.38) and T. durum (0.35) than between the latter two populations (0.19) (Table 3). In addition, significant differentiation among the populations was demonstrated using the permutation test with $K W$ diversity $(P=$ $0.001)$, including less significant differentiation among isolates from $T$. aestivum and $T$. durum $(P=0.05)$.

SSR data. Of the 10 SSR markers tested, only seven amplified in a sufficient number of genotypes to be useful. BGT-2, BGT-8, and BGT-9 had more than $40 \%$ missing data and were not analyzed. This contrasted with the performance of the same SSR markers on isolates from the United States, where all 10 primer pairs amplified fragments from all isolates (Parks et al. 2011).

Pairwise exact $G$ tests of population subdivision based on geographic origin found no significant differences between any sampling locations (Table 4). However, exact tests based on hosts indicated that, while isolates collected from $T$. aestivum and T. durum could not be distinguished from one another, both were significantly different from $T$. dicoccoides.

Structure Harvester analysis of Structure 2.3.3 runs provided additional support for an optimal K value of 2, based on Delta K. Data from 10 runs were summarized using CLUMPP and were visualized using distruct 1.1 (Fig. 5). A clear clustering of isolates into two groups, wild and domesticated, was observed, although some isolates from the wild-origin hosts were assigned to the domesticated group with a high probability and, in one case, vice versa. PCoA of the dissimilarity matrix largely mirrored the Structure barplot results (Fig. 6). They both indicated that T. aestivum and T. durum isolates tended to cluster with each other, as did $T$. dicoccoides isolates with each other, although the two groupings overlapped. For example, three $T$. durum-originated $B$. graminis f. sp. tritici isolates $(25,61$, and 97) were positioned with the wild-origin $B$. graminis f. sp. tritici group. Similarly, three wild-origin $B$. graminis f. sp. tritici isolates $(92,103$, and 208) were distributed proximal to the domestic-origin B. graminis f. sp. tritici group (Fig. 6).

SNP analysis. The $B$. graminis $\mathrm{f}$. sp. hordei isolate A6 produced a polymerase chain reaction product only at one locus (I12_G2). At that locus, a strong SNP polymorphism was detected between this isolate and the $B$. graminis f. sp. tritici isolates (data not shown).

In general, the molecular diversity in the $B$. graminis f. sp. tritici assay was low. Thirty-two SNPs were detected: 11 in the genic sequences, 21 in the intergenic regions. Four SNPs divided the collection into two major haplotypes (data not shown). This discrimination was only partly based on wheat host species. The rest of the SNPs divided a small group of several isolates from the rest

TABLE 4. Exact tests of population subdivision by geographic location and host of origin of 58 Blumeria graminis f. sp. tritici isolates collected in Israel, analyzed with simple-sequence repeat markers

\begin{tabular}{lccc}
\hline Populations & $\chi^{2}$ value & df & $P$ value \\
\hline Geographic regions $^{\mathrm{y}}$ & & & \\
EBS and EGAL & 18.9 & 14 & 0.17 \\
EBS and J\&P & 17.5 & 14 & 0.23 \\
EGAL and J\&P & 16.0 & 14 & 0.31 \\
EBS and NCP & 8.0 & 12 & 0.79 \\
EGAL and NCP & 13.6 & 12 & 0.33 \\
J\&P and NCP & 21.9 & 14 & 0.08 \\
Host of origin & & & \\
AES and DIC & 75.2 & 14 & 0.00 \\
AES and DUR & 11.4 & 14 & 0.66 \\
DIC and DUR & 40.5 & 14 & 0.00 \\
\hline
\end{tabular}

${ }^{\text {y }}$ EBS $=$ Emek Bet Shean, EGAL = Eastern Galilee, J\&P = Mt. Judea and Plains, and NCP = Northern Coastal Plain.

z $\mathrm{AES}=$ Triticum aestivum, $\mathrm{DIC}=T$. dicoccum, and DUR $=T$. durum. of the collection. In seven cases, a single isolate was separated from the rest of the collection based on a SNP.

There was a strong congruence in the clustering of isolates by virulence and SNP data (Fig. 7). Among the 34 isolates for which both virulence profiles and SNP haplotypes were available, there were only two isolates that did not appear either above or below the dividing line for both types of data (Fig. 7).

Migration. Using Migrate- $\mathrm{N}$, a test for subdivision of the T. aestivum and T. durum populations determined that they form a single population, i.e., panmixia best fit the data from those two populations alone $(P>0.99$ for both marker types). In subsequent analyses, the $T$. aestivum and $T$. durum data were pooled, and migration was assessed between the two populations originating from domestic wheat and $T$. dicoccoides, respectively. Four models each were tested for SNPs and SSRs: panmixia, two-way migration, one-way migration from domestic wheat to $T$. dicoccoides, and oneway migration in the other direction. For both marker types, the bestfitting model was one-way migration of mildew from domestic wheat to $T$. dicoccoides $(P \geq 0.99)$.

Estimates of population size $(\Theta)$ and migration rate $(\mathrm{M})$ diverged in opposite directions for the two types of markers, with SNPs leading to a larger estimated effective population for B. graminis f. sp. tritici derived from domestic hosts, and SSRs producing a larger estimated effective population for strains from wild emmer (Table 5). Overall, SNPs yielded estimates of small effective populations but a high migration rate, and the opposite was true for SSRs. Consequently, the estimated numbers of migrants per generation for the two marker types were very similar (five to six migrants per generation from domesticated wheats to T. dicoccoides).

\section{DISCUSSION}

To our knowledge, this is one of the first in-depth analyses of hostrange differentiation within a Blumeria graminis forma specialis. $B$. graminis f. sp. tritici isolates separated into two distinct groups based on host of origin: domesticated wheat (T. durum and T. aestivum) and wild wheat (T. dicoccoides). This pattern was consistent across every analysis performed on virulence, microsatellite, or sequence data. Given that the two types of hosts have coexisted sympatrically in Israel for around 8,000 years, this genetic separation by host species could be evidence of separate coevolution of $B$. graminis f. sp. tritici on its ancestral and cultivated hosts following domestication of the latter. However, given the significant one-way migration that was detected, the genetic separation is more likely due, at least in part, to strong genetic drift in populations of wild $B$. graminis $\mathrm{f}$. sp. tritici founded by those relatively few "domesticated" immigrants able to survive and reproduce on $T$. dicoccoides. Today, the distribution of

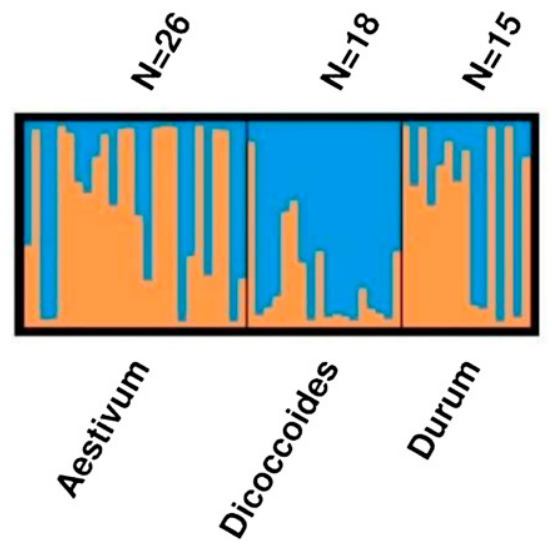

Fig. 5. Clustering of 61 Blumeria graminis f. sp. tritici isolates from Israel by STRUCTURE, showing two primary groups, wild origin (from Triticum dicoccoides) and domestic origin (from T. aestivum or T. durum). 
wild emmer wheat habitats is limited, in most cases, to higher elevations and heavy soils. This, in addition to other factors, has contributed to the formation of eco-geographically distinct wheat niches in the wild and in domesticated fields. The specific attributes of each niche represent different adaptive challenges to wheat and its obligate biotroph that underlie the differentiation of wild and domesticated B. graminis f. sp. tritici.
Menardo et al. (2016) analyzed full genomic sequences of 17 of the isolates in our dataset $(n=61)$ and found that most isolates originating from $T$. dicoccoides (six of eight) were strongly differentiated from other B. graminis f. sp. tritici isolates. Based on these results, they defined a new forma specialis, $B$. graminis f. sp. dicocci, growing exclusively on tetraploid wheat. However, in the current study, which included the isolates studied by

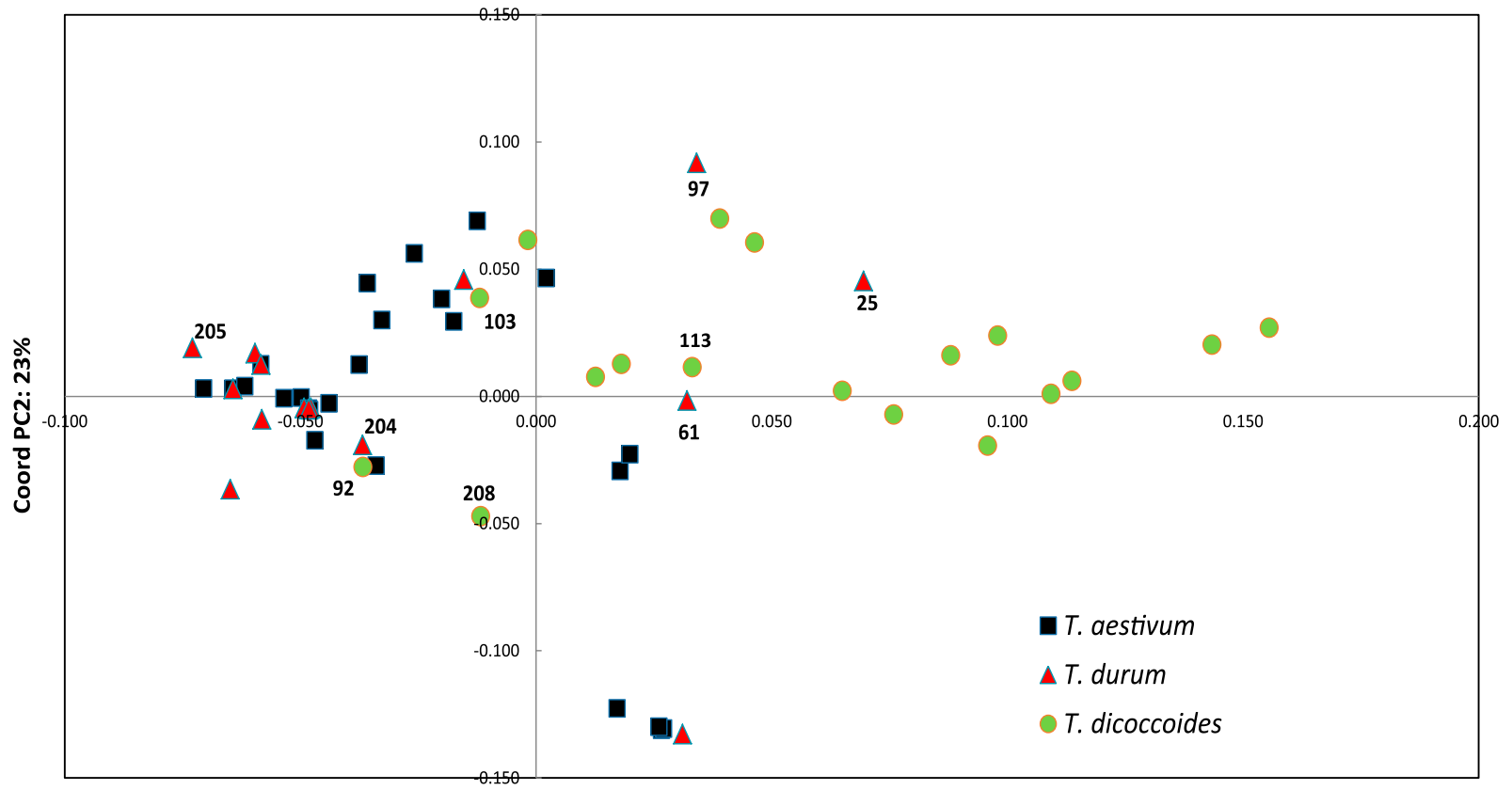

Coord PC1: $32 \%$

Fig. 6. Genetic diversity analysis of 58 Blumeria graminis f. sp. tritici isolates based on data from the seven simple-sequence repeat (SSR) markers. Principal coordinates analysis was implemented using the step-wise mutation model to measure dissimilarities between SSR profiles. B. graminis f. sp. tritici isolates originated from wild wheat (Triticum dicoccoides, green circles), domesticated durum wheat ( $T$. durum, red triangles), or bread wheat (T. aestivum, dark squares). Together, the two principal coordinates account for 55\% of the genetic variance among isolates. Isolates mentioned in the text are labeled.

A

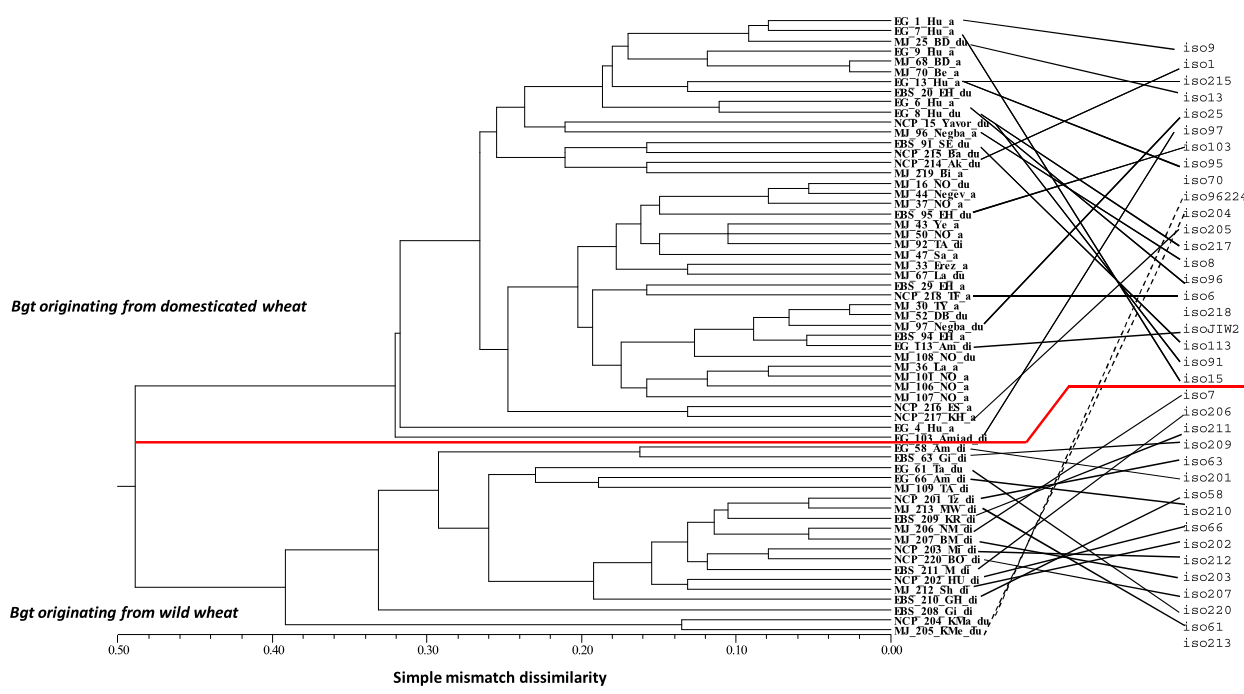

B

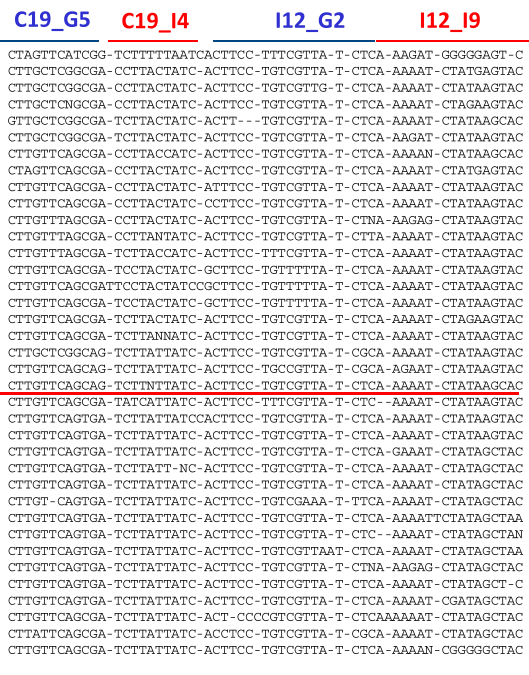

Fig. 7. Congruence of virulence and single-nucleotide polymorphism profiles of Blumeria graminis f. sp. tritici isolates from Israel and vicinity. A, Simplemismatch dissimilarity dendrogram of virulence scores of 61 isolates created with the virulence analysis tool (VAT). Of the 61 isolates, 19 were sampled from wild emmer wheat and 42 from domesticated wheat. B, Multilocus clustalW analysis of blue genic (C19_G5 and I12_G2) and red intergenic (C19_I4 and I12_I9) sequences of 37 B. graminis f. sp. tritici isolates. Of the 37 isolates, 15 were sampled from wild emmer wheat and 22 from domesticated wheat. B. graminis f. sp. tritici isolates from domesticated and wild wheat are consistently either above or below the red line, respectively, with few exceptions. Solid black lines $=$ isolate aligned similarly by both analyses; dotted black lines = isolates aligned differently. 
Menardo et al. (2016), we did not find B. graminis f. sp. tritici isolates that grew exclusively on tetraploid wheat species, and thus our results do not support the conclusion of Menardo et al. (2016) that there is a distinct forma specialis pathogenic uniquely on tetraploid wheat. This discrepancy could be at least partly explained by the limited overlap between the two studies in terms of virulence data. Of the 36 wheat lines that were included in our virulence study, only three were also tested by Menardo et al. (2016).

In addition to the existence of two distinct groups of $B$. graminis $\mathrm{f}$. sp. tritici, domestic and wild, some outlier genotypes were observed, i.e., isolates from $T$. dicoccoides that clustered with isolates from domesticated hosts and vice versa. These may be the result of the significant gene flow that was detected from populations in cultivated wheat fields to populations on wild emmer. Despite this level of one-way gene flow, the virulence profile of the wild emmer-derived B. graminis f. sp. tritici population still diverged significantly from that of the domestic wheat-derived population. The virulence profile in our study was determined on the basis of interactions with several $P m$ genes that probably do not exist in wild emmer and, thus, the virulence complexity (VC) of the wild wheat-derived isolates was naturally low. The isolates derived from domesticated wheat were more adapted to at least several of the $P m$ genes, and therefore their VC was higher.

It could be hypothesized that the virulences to $P m$ genes found in cultivated wheats are not advantageous and entail a fitness cost to $B$. graminis f. sp. tritici isolates that are established on wild emmer, because the latter host possesses a partially differing suite of resistance genes. In that scenario, the domestic $B$. graminis f. sp. tritici strains lose the unnecessary virulences through sexual recombination once they become established on wild emmer. Alternatively, it is possible that $P m$-virulent domestic $B$. graminis f. sp. tritici strains are selected against on wild emmer and it is mainly low-VC domestic $B$. graminis f. sp. tritici isolates that establish on wild emmer and contribute to the "wild" B. graminis f. sp. tritici gene pool. Either or both explanations are compatible with the lower virulence frequencies and lower VC on wild emmer-derived B. graminis f. sp. tritici isolates. In an evolutionary context, it is also possible that the wild emmer-derived $B$. graminis f. sp. tritici strains with higher VC represent the ancestral portion of the $B$. graminis $\mathrm{f}$. sp. tritici population on wild wheat from which mildew of domesticated wheat eventually evolved. However, as indicated earlier, the VC data should be interpreted with caution, as the differential set contained only a few wild emmer wheat lines.

A notable finding of this study was the absence of support for B. graminis $\mathrm{f}$. $\mathrm{sp}$. tritici migration from $T$. dicoccoides into the domesticated wheat populations of $B$. graminis f. sp. tritici, despite the spatial proximity of these host populations. There were a few anomalous cases: one isolate (61) had the virulence, SSR, and SNP alleles of a wild strain and clustered with emmer-derived isolates, but was sampled from a T. durum landrace cultivar (Figs. 6 and 7). Interestingly, this isolate (61) was also an exception in a previous study (Eshed et al. 1994): originating from domesticated wheat but with virulence attributes and genetic profile similar to isolates from wild emmer wheat. Isolate 61 was collected from a durum wheat landrace (sampled in 1990 from Zenati Bouteille) in the eastern Galilee, a region with a long history of durum-based traditional dryland farming. This region is also dominated by large populations of wild wheat. Thus, the region provides an intimate geographic proximity between wild and domesticated wheats, in which wild wheat plants invade wheat fields and grow as weeds on their margins. This pattern enables not only spontaneous introgressions of wild emmer into durum, but also the movement and adaptation of the mildew pathogen.

In order for a migrant to be successful, it must contribute alleles to the next generation, so isolate 61 does not, by itself, provide evidence for migration, but it still might have been the result of an appreciable amount of inoculum spreading from wild-emmer into wheat fields. Isolates 204 and 205 were sampled in 2010 from the T. durum cultivar Eylon in different geographical zones not so much in proximity to wild emmer. Their virulence haplotypes were similar to those of wild B. graminis f. sp. tritici isolates; they were avirulent to a number of $P m$ genes (e.g., $P m 1, P m 3$, and $P m 4$ ). However, isolates 204 and 205 were clearly classified by SSR and SNP data with isolates from domesticated hosts (Figs. 6 and 7), and so, these isolates could represent the successful contribution of avirulence alleles by a wild migrant or migrants to the domestic population, pending on the absence of the relevant $P m$ genes. Two other T. dicoccoides-derived isolates (103 and 113) clustered with the T. aestivum-derived isolates based on virulence data and could have been derived from migration from cultivated to wild populations. For isolate 103, this pattern was also evident in both molecular assays, while for isolate 113 it was present for SNP data (Fig. 7) but not for SSRs (Fig. 6). Isolate 92, which showed a pattern similar to that of 103, was collected from a wild emmer wheat plant in a nursery at Tel-Aviv University; its habitat was thus not natural and it could be considered an exception.

Two factors likely account for the dominance of one-way migration here: (i) the much larger production area of domesticated wheat in Israel and (ii) the contrast between the genotypically uniform expanses of cultivated bread and durum wheats, in which a virulent clone can build up very large spore populations within a season, and the genotypically diverse populations of $T$. dicoccoides, in which rates of epidemic expansion are more limited, due to the intimate mixtures of resistant (in most cases nonhost) and susceptible plants within natural habitats (Fig. 2). While our results are ambiguous with respect to whether domestic or wild hosts support a larger $B$. graminis $\mathrm{f}$. sp. tritici effective population (Table 5), B. graminis f. sp. tritici on domesticated wheat clearly produces larger spore populations, ensuring a greater likelihood that any given new infection will be caused by a strain originating from domestic hosts.

Given the considerable gene flow detected, the genetic differentiation of cultivated and wild $B$. graminis f. sp. tritici populations requires an explanation. Evolutionary forces resulting in this differentiation may include (i) infrequent wild-to-domestic infection, as the population on wild emmer lacks the necessary virulence mutations, (ii) meager wild-to-domestic spread of mildew inoculum, due to the much smaller populations of both host and

TABLE 5. Migration of Blumeria graminis f. sp. tritici isolates collected in Israel from domestic Triticum species (source) to wild emmer wheat (sink) as estimated by two types of molecular markers ${ }^{\mathrm{y}}$

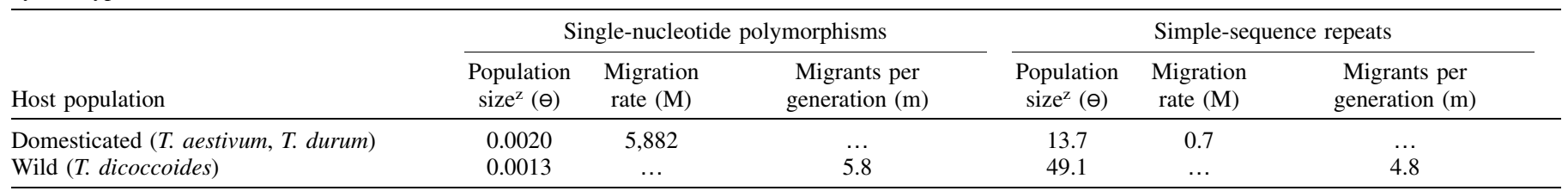

${ }^{\mathrm{y}}$ Best-fitting migration model: T. aestivum and T. durum are a single population and all migration is from the domesticated hosts to T. dicoccoides $(P \geq 0.99)$.

Values are modes of parameter estimates.

${ }^{\mathrm{z}}$ Mutation-scaled effective population size. 
parasite, (iii) possible mating-type incompatibility, limiting sexual reproduction and transmittal of alleles when cross-host infections occur, and (iv) loss of migrant alleles due to population bottlenecks caused by low, sporadic mildew occurrence in the Israeli environment, especially in wild habitats (Fig. 2). It seems likely that, while relatively many domestic $B$. graminis f. sp. tritici spores land on $T$. dicoccoides plants, only a small percentage of them survive, due both to a hostile climate and to the suite of resistance genes in wild emmer. These genes may, indeed, be $P m$ genes of the nucleotide binding site-leucine-rich repeat type that constitute the bridge between host and nonhost resistance in closely related host species described by Schulze-Lefert and Panstruga (2011). The small set of domestic survivors may found wild populations subject to strong genetic drift, which could at least partially account for the differentiation of the two populations. Basically, even when successful domestic-to-wild migrants mate and supply genes to the next generation, the migrant alleles remain rare and can be lost in the event of a population bottleneck. Nevertheless, migration continues at a rate thus far sufficient to prevent greater divergence of the two populations, at least within the study area of sympatric wild and domestic Triticum spp. It would be interesting to expand the survey area to include the cultivated wheat and wild emmer B. graminis f. sp. tritici populations in the Turkish, Iraqi, and Iranian regions comprising the remainder of wild emmer's natural range (Ozkan et al. 2011), in order to see if the differentiation we detected is also present there.

The two molecular assays produced similar results except with respect to the migration analyses. Based on SNPs, the domestic wheat $B$. graminis f. sp. tritici effective population was estimated to be about 50\% larger than that derived from $T$. dicoccoides. With SSRs, however, the emmer-derived population was estimated to be nearly four times larger than the population originating on domestic wheat. The smaller effective population sizes and higher migration rate based on SNPs likely reflects the more ancient origins of these polymorphisms, as compared with the relatively recent SSR polymorphisms. Low diversity of SNPs was in line with what was previously found in mildew isolates from the U.S. (Parks et al. 2008). Due to their associations with transposable elements (Buschiazzo and Gemmell 2006), which constitute over $90 \%$ of the B. graminis f. sp. tritici genome (Parlange et al. 2011; Wicker et al. 2013), SSRs likely have a higher rate of evolution than SNPs, and the present isolate sample would thus give rise to a larger inferred effective population size using SSRs than SNPs.

In any case, the estimate of five to six migrants per generation is relatively high, indicating that there is substantial gene flow from B. graminis f. sp. tritici populations in domesticated wheat fields to those in the wild emmer populations of Israel. For comparison, estimates from other airborne ascomycetous plant pathosystems include 0.5 to 1.7 from SSRs and intergenic spacer sequences on Sclerotinia sclerotiorum populations in nine United Kingdom locations (Clarkson et al. 2013) and between 0.76 and 7 for Dothistroma septosporum in Estonia, Finland, and the Czech Republic (Drenkhan et al. 2013) (although values for the latter should apparently have been divided by two, the inheritance scalar for a haploid organism). Of course, the $B$. graminis f. sp. tritici populations studied here are intermixed on a much smaller and finer geographic scale than in the other examples.

The geographic factor of $B$. graminis f. sp. tritici isolates sampled from different regions within Israel was nonsignificant in explaining both molecular and pathotypic variation. This suggests that the $B$. graminis $\mathrm{f}$. sp. tritici population of Israel is well-mixed and randomly mating across the study area, which makes sense given the small size of the region sampled.

In conclusion, the $B$. graminis $\mathrm{f}$. sp. tritici population of Israel was found to be panmictic on durum and common wheat, but genetically differentiated between isolates originating from domestic and those from wild emmer wheat. Both virulence profiles and neutral genetic markers confirmed a partial separation into these two groups. Gene flow occurs from the domestic wheat $B$. graminis f. sp. tritici population to the wild population and the rate may be sufficient to prevent the two groups from diverging into separate formae speciales.

\section{APPENDIX}

The analysis of genetic diversity with SSR markers requires an appropriate assessment of allelic dissimilarity. Given the stepwise mutation model, the first step is measuring differences between any two SSR alleles. Let $a s_{i j}$ be allele size of allele $i$ at locus $j$, and $l t r_{j}$ be the length of the tandem repeat unit at locus $j$; then the difference between alleles $i$ and $k$ at that locus is calculated as $\left|a s_{i j}-a s_{k j}\right| / l t r_{j}$, which is the difference in the number of tandem repeats in the two alleles. This can be considered an approximation of the number of mutation events (tandem repeat insertions or deletions that are not reversed) that result in the transformation of allele $i$ into allele $k$. If the maximum number of tandem repeats (mutation events) varies from locus to locus, one can assume that the mutation rate is also variable and locusspecific. Therefore, a particular value of the difference between two SSR alleles should have a greater impact on dissimilarity between isolates at loci where changes happen more slowly. In other words, a larger maximum number of tandem repeats tr_max $\operatorname{mas}_{j}$ at locus $j$ as compared with the maximum at another locus, given the same interval of evolutionary time, is interpreted as a higher mutation rate at locus $j$. Thus, we normalize $\left|a s_{i j}-a s_{k j}\right| / l t r_{j}$ by tr_max ${ }_{j}(a s)$, so that the difference between two SSR alleles $i$ and $k$ at locus $j$ equals

$$
\begin{aligned}
\rho_{i k j} & =\frac{\left|a s_{i j}-a s_{k j}\right| / l t r_{j}}{t r_{-} m a x_{j}(a s)}=\frac{\left|a s_{i j}-a s_{k j}\right| / l t r_{j}}{\left[\max _{j}(a s)-\min _{j}(a s)\right] / l t r_{j}} \\
& =\frac{\left|a s_{i j}-a s_{k j}\right|}{\max _{j}(a s)-\min _{j}(a s)}
\end{aligned}
$$

where $\max _{j}(a s)$ and $\min _{j}(a s)$ are the maximum and minimum allele sizes, respectively, detected at locus $j$. Now, the dissimilarity between microsatellite patterns of two isolates $i$ and $k$ with profiles $\left(a s_{i 1}, a s_{i 2}, \ldots, a s_{i n}\right)$ and $\left(a s_{k 1}, a s_{k 2}, \ldots, a s_{k n}\right)$ at $n$ loci is determined as follows

$$
\rho_{i k}=\frac{1}{n} \cdot \sum_{j=1}^{n} \rho_{i k j}=\frac{1}{n} \cdot \sum_{j=1}^{n} \frac{\left|a s_{i j}-a s_{k j}\right|}{\max _{j}(a s)-\min _{j}(a s)}
$$

\section{ACKNOWLEDGMENTS}

This work was supported by University Research Priority Program Systems Biology/Functional Genomics grants, University of Zurich, an Advanced Investigator Grant from the European Research Council (ERC2009-AdG 249996, Durable resistance) and by the United States Department of Agriculture-Agricultural Research Service.

\section{LITERATURE CITED}

Beerli, P., and Palczewski, M. 2010. Unified framework to evaluate panmixia and migration direction among multiple sampling locations. Genetics 185: 313-326.

Ben-David, R. 2011. Molecular mapping of powdery mildew resistance genes derived from the Triticum turgidum gene pool. Ph.D. thesis, The University of Haifa, Haifa, Israel.

Ben-David, R., Peleg, Z., Dinoor, A., Saranga, Y., Korol, A. B., and Fahima, T. 2014. Genetic dissection of quantitative powdery mildew resistance loci in tetraploid wheat. Mol. Breed. 34:1647-1658.

Ben-David, R., Peleg, Z., Xie, W., Saranga, Y., Dinoor, A., Korol, A. B., and Fahima, T. 2008. Dissection of powdery mildew resistance uncover different resistance types in the Triticum turgidum L. gene pool. Proceedings of the 11th International Wheat Genetics Symposium. R. Appels, R. Eastwood, 
E. Lagudah, P. Langridge, M. Mackay, L. McIntyre, and P. Sharp, eds. Sydney University Press, Sydney. http://wheat.pw.usda.gov/GG2/Triticum/ events/11IWGS/

Buschiazzo, E., and Gemmell, N. J. 2006. The rise, fall and renaissance of microsatellites in eukaryotic genomes. BioEssays 28:1040-1050.

Clarkson, J. P., Coventry, E., Kitchen, J., Carter, H. E., and Whipps, J. M. 2013. Population structure of Sclerotinia sclerotiorum in crop and wild hosts in the UK. Plant Pathol. 62:309-324.

Cowger, C., Parks, R., and Kosman, E. 2016. Structure and migration in U.S. Blumeria graminis f. sp. tritici populations. Phytopathology 106:295-304.

Drenkhan, R., Hantula, J., Vuorinen, M., Jankovský, L., and Müller, M. M. 2013. Genetic diversity of Dothistroma septosporum in Estonia, Finland and Czech Republic. Eur. J. Plant Pathol. 136:71-85.

Earl, D. A., and vonHoldt, B. M. 2012. STRUCTURE HARVESTER: A website and program for visualizing STRUCTURE output and implementing the Evanno method. Conserv. Genet. Resour. 4:359-361.

Eshed, N., Dinoor, A., and Litwin, Y. 1994. The physiological specialization of wheat powdery mildew in Israel and the search for mildew resistance in wild wheat, Triticum dicoccoides. Phytoparasitica 22:75.

Eshed, N., and Wahl, I. 1970. Host ranges and interrelations of Erysiphe graminis hordei, Erysiphe graminis tritici, and Erysiphe graminis avenae. Phytopathology 60:628-634.

Evanno, G., Regnaut, S., and Goudet, J. 2005. Detecting the number of clusters of individuals using the software structure: A simulation study. Mol. Ecol. 14:2611-2620.

Harlan, J. R., and Zohary, D. 1966. Distribution of wild wheat and barley. Science 153:1074-1080.

Hsam, S. L. K., and Zeller, F. J. 1997. Evidence of allelism between genes Pm8 and Pm17 and chromosomal location of powdery mildew and leaf rust resistance genes in the common wheat cultivar 'Amigo'. Plant Breed. 116:119-122.

Inuma, T., Khodaparast, S. A., and Takamatsu, S. 2007. Multilocus phylogenetic analyses within Blumeria graminis, a powdery mildew fungus of cereals. Mol. Phylogenet. Evol. 44:741-751.

Kosman, E. 1996. Difference and diversity of plant pathogen populations: A new approach for measuring. Phytopathology 86:1152-1155.

Kosman, E. 2014. Measuring diversity: From individuals to populations. Eur. J. Plant Pathol. 138:467-486.

Kosman, E., Ben-Yehuda, P., and Manisterski, J. 2014. Diversity of virulence phenotypes among annual populations of wheat leaf rust in Israel from 1993 to 2008. Plant Pathol. 63:563-571.

Kosman, E., and Leonard, K. J. 2007. Conceptual analysis of methods applied to assessment of diversity within and distance between populations with asexual or mixed mode of reproduction. New Phytol. 174: 683-696.

Mains, E., and Dietz, S. 1930. Physiologic forms of barley mildew, Erysiphe graminis hordei Marchal. Phytopathology 20:229-239.

Marchal, E. 1902. De la specialization du parasitisme chez l'Erysiphe graminis. Comp. Rend. Acad. Sci. (Paris) 135:210-212.

Matschiner, M., and Salzburger, W. 2009. TANDEM: Integrating automated allele binning into genetics and genomics workflows. Bioinformatics 25: 1982-1983.

Menardo, F., Praz, C. R., Wyder, S., Ben-David, R., Bourras, S., Matsumae, H., McNally, K. E., Parlange, F., Riba, A., Roffler, S., Schaefer, L. K., Shimizu, K. K., Valenti, L., Zbinden, H., Wicker, T., and Keller, B. 2016. Hybridization of powdery mildew strains gives rise to pathogens on novel agricultural crop species. Nat. Genet. 48:201-205.
Oberhaensli, S., Parlange, F., Buchmann, J. P., Jenny, F. H., Abbott, J. C., Burgis, T. A., Spanu, P. D., Keller, B., and Wicker, T. 2011. Comparative sequence analysis of wheat and barley powdery mildew fungi reveals gene colinearity, dates divergence and indicates host-pathogen co-evolution. Fungal Genet. Biol. 48:327-334.

Oku, T., Yamashita, S., Doi, Y., and Nishihara, N. 1985. Host range and forma specialis of cocksfoot powdery mildew fungus (Erysiphe graminis DC) found in Japan. Ann. Phytopathol. Soc. Jpn. 51:613-615.

Özkan, H., Willcox, G., Graner, A., Salamini, F., and Kilian, B. 2011. Geographic distribution and domestication of wild emmer wheat (Triticum dicoccoides). Genet. Resour. Crop Evol. 58:11-53.

Parks, R., Carbone, I., Murphy, J. P., and Cowger, C. 2009. Population genetic analysis of an Eastern U.S. wheat powdery mildew population reveals geographic subdivision and recent common ancestry with U.K. and Israeli populations. Phytopathology 99:840-849.

Parks, R., Carbone, I., Murphy, J. P., Marshall, D., and Cowger, C. 2008. Virulence structure of the eastern US wheat powdery mildew population. Plant Dis. 92:1074-1082.

Parks, W., Booth, W., and Cowger, C. 2011. Characterization of polymorphic loci of Blumeria graminis f. sp. tritici, the cause of powdery mildew in wheat. Mol. Ecol. Resour. 11:586-589.

Parlange, F., Oberhaensli, S., Breen, J., Platzer, M., Taudien, S., Šimková, H., Wicker, T., Doležel J., and Keller, B. 2011. A major invasion of transposable elements accounts for the large size of the Blumeria graminis f. sp. tritici genome. Funct. Integr. Genomics 11:671-677.

Peng, J., Sun, D., and Nevo, E. 2011. Wild emmer wheat, Triticum dicoccoides, occupies a pivotal position in wheat domestication process. Aust. J. Crop Sci. 5:1127-1143.

Salamini, F., Özkan, H., Brandolini, A., Schäfer-Pregl, R., and Martin, W. 2002. Genetics and geography of wild cereal domestication in the Near East. Natl. Rev. 3:429-441.

Schachtel, G. A., Dinoor, A., Herrmann, A., and Kosman, E. 2012. Comprehensive evaluation of virulence and resistance data: A new analysis tool. Plant Dis. 96:1060-1063.

Schulze-Lefert, P., and Panstruga, R. 2011. A molecular evolutionary concept connecting nonhost resistance, pathogen host range, and pathogen speciation. Trends Plant Sci. 16:117-125.

Troch, V., Audenaert, K., Wyand, R. A., Haesaert, G., Höfte, M., and Brown, J. K. M. 2014. Formae speciales of cereal powdery mildew: Close or distant relatives? Mol. Plant Pathol. 15:304-314.

Walker, A. S., Bouguennec, A., Confais, J., Morgant, G., and Leroux, P. 2011. Evidence of host-range expansion from new powdery mildew (Blumeria graminis) infections of triticale $(\times$ Triticosecale) in France. Plant Pathol. 60: 207-220.

Wicker, T., Oberhaensli, S., Parlange, F., Buchmann, J. P., Shatalina, M., Roffler, S., Ben-David, R., Dolezel, J., Simkova, H., Schulze-Lefert, P., Spanu, P. D., Bruggmann, R., Amselem, J., Quesneville, H., Ver Loren van Themaat, E., Paape, T., Shimizu, K. K., and Keller, B. 2013. The wheat powdery mildew genome shows the unique evolution of an obligate biotroph. Nat. Genet. 45: 1092-1096.

Wyand, R. A., and Brown, J. K. 2003. Genetic and forma specialis diversity in Blumeria graminis of cereals and its implications for host-pathogen coevolution. Mol. Plant Pathol. 4:187-198.

Zohary, D., and Hopf, M. 2000. Domestication of plants in the old world: The origin and spread of cultivated plants in west Asia, Europe, and the Nile valley, 3rd Ed. Oxford University Press, Oxford. 